\title{
Awareness of palliative care among general practioners of Bhopal: a cross sectional study
}

\author{
Jain $\mathbf{R}^{1}$, Ratre $\mathbf{B K}^{2}$, Patel $\mathbf{N P}^{3}$ \\ ${ }^{1}$ Dr Roopesh Jain, Associate Professor of Anaesthesiology, ${ }^{2}$ Dr Bhupendra Kumar Ratre, Associate Professor of \\ Medicine, ${ }^{3}$ Dr Narmada Prasad Patel, Associate Professor of Medicine, all authors are affiliated with LN Medical \\ College, Bhopal, MP, India.
}

Address for Correspondence: Dr Narmada Prasad Patel, Email: narmadapatel2006@rediffmail.com

\begin{abstract}
Introduction: Palliative medicine is one of the developing medical specialities. This study was undertaken to enquire about the level of awareness regarding various aspects of palliative care among general practitioners of city of Bhopal. Material and method: This study was undertaken with the help predesigned questionnaire among the general practioners enquiring them about various aspects of Palliative medicine. Results: The opinion about diseases requiring palliative care varied to large extent. Majority of subject reported pain control as the main objective of palliative care. There were varied response to various other aspects of palliative care but majority had considered it important. Discussion: Palliative care is an important aspect of comprehensive care which needs to be given to terminally ill patients. Awareness regarding same variable even among doctors and improved awareness through various means is essential to improve quality of life of patients and their families facing the problems associated with life-threatening illness.
\end{abstract}

Keywords: Palliative care, Hospice, Analgesia, Terminally ill, Quality of life

\section{Introduction}

Palliative medicine is one of the developing medical specialties. World Health Organization (WHO) defines palliative care as an approach that improves the quality of life of patients and their families facing the problems associated with life-threatening illness, through prevention and relief of suffering by means of early identification, assessment and treatment of pain, and other problems - physical, psychosocial, and spiritual. Palliative care starts as supportive care at the time of diagnosis of life-threatening illness and continues as terminal care if the illness progresses until death of the patient [1]. In developed countries doctors held guilty of serious professional misconduct because they have been unable to provide palliative medicine or refer for specialist palliative medicine [2]. It is estimated that in India the total number of people who need palliative care is likely to be 5.4 million people a year. Though palliative care services have been in existence for many

Manuscript received: $20^{\text {th }}$ June 2016

Reviewed: $27^{\text {th }}$ June 2016

Author Corrected: $6^{\text {th }}$ July 2016

Accepted for Publication: $14^{\text {th }}$ July 2016 years, India ranks at the bottom of the Quality of Death index in overall score. However there has been steady progress in the past few years through communityowned palliative care services. The concept of palliative medicine is not new. In the modern world, many developed countries do not consider cancer services provision appropriate until the services have the back up of palliative medicine teams [3]. Many developing countries do recognize the need for palliative medicine. India is running well-designed teaching programs with the establishment of Indian Association of Palliative Care [4]. This article shows the results of a survey undertaken to enquire about the level of awareness regarding various aspects of palliative care among general practitioners of Bhopal through a questionnaire.

\section{Material and Methods}

A questionnaire [Table 1] was developed by us. Ethical committee clearance was obtained from Institutional Ethics Committee Board. The questionnaire was 
internally validated by a pilot study done in Department of Anaesthesiology, LN Medical College, Bhopal. After some time another larger sample was taken from general practitioners. Questionnaire was distributed, by hand and via mail, to general practitioners of Bhopal. The distribution and collection of questionnaires was carried out within two months. The questionnaire was designed to get a wider number of responses in a relatively short time and at lower cost.

\section{Table-1: Questionnaire}

1. Degree of doctor

2. Numbers of Years of medical practice

3. Experience in palliative care

4. Have you ever been involved in palliative care of patients (Yes/No)

5. Most important symptom to be contolled in Palliative care

6. What are the diseases requiring palliative care ?

7. Whether you disclose about breaking bad news? (Yes/No)

8. Whether you enjoyed your interaction with patients of palliative care ?(Yes/No)

9. Future of palliative care

10. For treatment plan of terminally ill you involve specialist/patient/Family

11. How to do pain management for palliative care of cancer patients

\section{Results}

Of the 600 questionnaires sent, 540 (90\%) were returned.

After recording the demographic data, they were asked questions about:

- Why to provide palliative care (diseases and aims)

- Their experience of palliative care

- Ethical aspect of palliative care

- Pain management

- Different aspect of terminal care (Hospice etc.).

The diseases, for which doctors think palliative care was important, ranged enormously. The most frequently mentioned diseases requiring palliative care, was cancer $(52 \%)$, stroke $(38 \%)$ and neurodegenerative disease $(10 \%)$.

Four hundred eighty doctors $(80.0 \%)$ mentioned about pain control as the primary aim for palliative care management. When they were asked whether they were enjoying their experience with palliative medicine, 300 doctors $(50.0 \%)$ stated that they were enjoying their experience with palliative care, while 180 doctors (30\%) were not happy with their experiences with palliative care, rest did not answer to this question. When asked about the future of palliative medicine, 552 doctors $(92 \%)$ thought that more and more people will be in need of palliative medicine in future.

When asked whether breaking bad news to the patient is necessary, 360 doctors (60\%) thought it was absolutely necessary. When asked whether they explained the prognosis of the disease in detail to the patient, 540 doctors $(90 \%)$ said they explained in details and fully to the patients.

Regarding decision making, only a few of them (25\%) said they took decision on their own while a majority (75\%) said they took decision in consultation with other specialities. Involving the patient too, in decision making was done by 240 doctors (30\%) while involvement of family in decision making was sought out by $70 \%$. When it came to the question that whether patient was the sole authority for decision making majority of them (80\%) replied negative.

When asked about the choice and sequence of the analgesia, in terminal cancer pain, correct sequence following WHO ladder of pain control only $25 \%$ stated the correct sequence of drugs, although a variety of other forms of pain control was also used by many of them.

The doctors were also asked whether they felt comfortable with any other form of treatment other than allopathic. Three hundred and sixty (60\%) doctors stated that they had no objection. The treatments mentioned by the doctors were spiritual, ayurvedic, acupuncture. Other forms of therapy mentioned were yoga, physiotherapy and physical therapy etc.

Lastly, the doctors' knowledge about the hospices was questioned. Four hundred and sixty two doctors (77.0\%) stated that they had heard about a hospice, although none had seen one and 78 of them (13\%) had never heard about a hospice. When asked about the preferred place of providing terminal care, 480 doctors (80\%) mentioned home and 30 doctors $(5 \%)$ choose hospice. Statistical tests on the data were not performed as the questions asked were open-ended with answers given on individual discretion. 


\section{Discussion}

Palliative medicine is now considered as comprehensive care of terminally ill. Like any other sub-speciality, palliative medicine training is an essential part of the medical undergraduate training. Palliative care aims to enhance the quality of life and positively influence the course of illness. Palliative care is used to describe supportive care when the disease is no longer responsive to curative treatment; thus, palliative care provides relief from pain and other distressing symptoms, affirms life, and regards dying as a normal process [1]. It offers a support system to help patients live as actively as possible until death and uses team approach to address the needs of the patients and their families. Palliative care is applicable early in case of illness in conjugation with other therapies that are intended to prolong life such as chemotherapy and radiotherapy. Pain relief is an extremely important component of palliative care, especially in the treatment of cancers. Palliative care offers a platform for communication with patient and families, rehabilitation to maximize independence, continuity of care, coordination between services, terminal care, and a support system to help families cope during patient illness and in bereavement. World Health Organization defined palliative medicine for the first time in 1990, as 'a facet of oncology, concerned with the control of symptoms rather than with the control of the disease' [5]. The present concept is to consider all the terminally ill, life-threatening diseases, but cancer remains the top reason for the need of palliative care.

Other diseases mentioned by the sample doctors like cerebrovascular accidents or old age are certainly not the cases for specialist palliative care. Other diseases for specialist palliative care teams are incurable neurological diseases e.g., multiple sclerosis, motor neuron disease and incurable infective diseases e.g., AIDS, multi-drug resistant tuberculosis etc., The findings of this survey indicate that the doctors need to be more aware of the disease that in need of palliative care.

In the survey the doctors mentioned pain management, prognosis explanation and rehabilitation as the main aims of palliative care. A study in developed country had indicated that these are the same aims identified by the general population in developed country [6]. The aim identified by the doctors themselves has been 'Quality of life as primary focus of palliative medicine'.
It is worth stressing that the quality of life should be subjective and multidimensional, dynamic, timespecific and is not defined by functional ability, performance status or cognition [7]. The findings of the survey indicate that the doctors are aware of the role of palliative care.

The results of the experience of palliative care were interesting. Seventy three percent of the doctors felt that they convey and explain in details the bad news to the patients. Studies have shown that $49 \%$ consultants have no formal training in breaking bad news and generally $70 \%$ of consultants felt that breaking bad news was inadequately done in the hospitals across developed countries [8]. Furthermore, there are no formal studies of any protocol to suggest the better way of doing this [9].

According to our questionnaire, $70 \%$ of the doctors mentioned that they involve the families and not only the patients in final plan of management. It is a wellestablished fact now that a psychologically competent patient has the right to know about their disease state. It is an ethical and legal requirement in many countries. [10] However, the doctors should not keep away their patients from the fact. It is evident from the literature that patients who are aware of their conditions accept the treatment and consequences better and also have improved quality of life [11]. There is risk that the patients would 'give up' after they are told about the diagnosis of a terminal illness. However studies suggest that usually these fears are unfounded and can cause more damage than harm. There are models which can help to provide quality of life after being told of terminal nature of disease [12]. It has been identified by healthcare professionals around the world and governing bodies like WHO, that families should be involved in gathering information about specific behavior that helps in patients' care (e.g., patients' like and dislikes, fears, concerns and beliefs etc.) [13]. Also, it is known that by sharing the information, the doctorpatient relationship will be good, which leads to uneventful terminal care. It is also evidenced that the doctors felt disturbed or disappointed, it must be realized that death is the only sure event in our lives. Dying is not a failure. It is dying with loss of dignity and in distressing symptoms, which is unacceptable [14]. The findings of this survey indicate that the doctors are confident about their knowledge of breaking 
bad news and importance of involving both the patient and his/her family in decision making. Further studies are required to establish the correct methodology for the same.

Regarding the pain management of terminally ill cancer patients, World Health Organization guidelines for managing cancer pain refer to a ladder pattern. At step one, it is recommended to administer non-opioids (e.g., Paracetamol), if necessary in addition of an adjuvant drug (e.g., NSAID). Step two recommendation for adding moderate opioids (e.g., Codeine, Tramadol etc.) and third step recommendation to administer strong opioids (e.g., Morphine) [15]. In many parts of India morphine availability is a problem, there are different other strong opioids e.g., Buprenorphine, Fentanyl etc are available .Lack of knowledge about the cancer pain is sometimes due to more stress on curative treatment and failure to accept the terminal nature of the illness and this is the most important barrier of availability of morphine freely in India $[16,17,18]$. Although, in our survey doctors identified various appropriate drugs, very few of them know WHO ladder for cancer pain management, which indicates that more and more such type of workshops are needed where one can get adequate knowledge about cancer pain management . Many studies suggests that ultimately patients of terminally cancer became pain free using this WHO ladder of cancer pain management [19]. In our survey we included the option for alternative therapy also.

There is no evidence that any complementary medicine can help curative treatment, but some techniques like aromatherapy, music therapy, acupuncture, relaxation therapy etc., have been helpful in managing the patients' suffering and mental distress [20]. In our country, the religious attachments are well established source of strength and well being [21]. This mechanism is also helpful in the bereavement phase. In the west, the bereavement support is provided by trained counselors but in east, extended families play an important role. The findings of this survey indicates that majority of the doctors respect the patients' right to alternative therapies.

Although more than $77 \%$ of the doctors had heard about a hospice, only $5 \%$ mentioned that hospice would be their patients' preferred place for dying. In fact, $80 \%$ mentioned that they would prefer home. This figure is very much culturally dependant. In Belgium, which is a Western European country, with lot of emphasis on individualism, data suggests that only $16 \%$ of the patients die at home, whereas $76 \%$ die in hospital/ nursing home [22]. In contrast to that, data from Italy which is a Mediterranean country with strong family values, shows that $86 \%$ of patients die at home and only $14 \%$ in hospital and nursing homes [23]. Wide availability of palliative care services should enable the patients to die at home, with their loved ones.

Hospitals have been felt too busy at times to deal with the dying patients. The findings of this survey indicate that doctors are conscious of the patients needs while making decisions about the venue of the patients last days.

The most promising aspect of this study was that all of participating doctors felt that need of short training on palliative care and frequent workshop would be beneficial to know and participate more and more in this type of care of terminally ill.

Indian society of palliative care is conducting foundation course and various workshops for spreading knowledge about palliative care.

Conclusion: There is a growing need of awareness and knowledge about palliative care. This need to be done by means of formal training of healthcare workers specially doctors to improve quality of life of critically ill patients and their families facing terminal illness. Foundation course and workshop dedicated for same may be helpful in this area.

\section{Funding: Nil, Conflict of interest: None. Permission of IRB: Yes}

\section{References}

1. Geneva: World Health Organization; 2007. Cancer Control: Knowledge into Action: WHO Guide for Effective Programmes: Module 3: Early Detection.

2. Riley J. The General Medical Council and the right to specialist palliative care. Palliat Med. 1997;11:317-18.

3. London: National Health Services; 2000. Manual of Cancer Services Standard.

4. Sureshkumar K, Rajagopal MR. Palliative care in Kerala. Problems at presentation in 440 patients with advanced cancer in a south Indian state. Palliat Med. 1996 Oct;10(4):293-8. 
5. Saunders C. London: Edward Arnold; 1984. Appropriate treatment, appropriate death: The management of terminal malignant disease.

6. Jarrett N, Payne S, Turner P, Hillier R. 'Someone to talk to' and 'pain control': what people expect from a specialist palliative care team. Palliat Med. 1999 Mar;13(2):139-44.

7. Waldron D, O'Boyle CA, Kearney M, Moriarty M, Carney D. Quality-of-life measurement in advanced cancer: assessing the individual. J Clin Oncol. 1999 Nov; 17(11):3603-11.

8. Barnett M. Netherlands: The Hague; 2003. Apr 3rd, Lecture at $8^{\text {th }}$ Congress of European Association of Palliative care.

9. Waitzkin H, Stoeckle JD. The communication of information about illness. Clinical, sociological, and methodological considerations. Adv Psychosom Med. 1987; 8:180-215.

10. Buckman R. 2nd ed. London: Oxford University Press; 1999. Communication in palliative care: A practical guide. Oxford Textbook of Palliative Medicine.

11. Weisman A. New York: McGraw-Hill; 1979. Coping with cancer.

12. Penson J. A hope is not a promise: fostering hope within palliative care. Int J Palliat Nurs. 2000 Feb; 6(2):94-8.

13. Wilson-Barnett J, Richardson A. London: Oxford University Press; 1999. Nursing research; pp. 98-104.
14. Sykes NP, Pearson SE, Chell S. Quality of care of the terminally ill: The carers' perspective. Palliative. 1992; 6:227-36.

15. Geneva: WHO; 1986. World Health Organisation. Cancer pain relief.

16. Dwyer L. Palliative medicine in India. Palliat Med. 1997 Nov;11(6):487-8.

17. Larue F, Colleau SM, Fontaine A, Brasseur L. Oncologists and primary care physicians' attitudes toward pain control and morphine prescribing in France. Cancer. 1995 Dec 1;76(11):2375-82.

18. Zenz M, Zenz T, Tryba M, Strumpf M. Severe undertreatment of cancer pain: a 3-year survey of the German situation. J Pain Symptom Manage. 1995 Apr; 10(3):187-91.

19. Takeda F. Results if filed-testing in Japan of the WHO draft interim guidelines on the relief of cancer pain. Pain Clin. 1986;1:83.

20. Fishman B. The treatment of suffering in patients with cancer pain. In: Foley K, Bonica J, Ventafridda V, editors. Advances in pain research and therapy. Vol. 16. New York: Raven Press; 1990. pp. 301-16.

21. Spilka B, Spangler JD, Nelson CB. Spiritual support in life threatening illness. J Relig Health. 1983 Jun; 22(2):98-104. doi: 10.1007/BF02296390.

22. Schrijvers D, Joosens E, Vandebroek J, Verhoeven A. The place of death of cancer patients in Antwerp. Palliat Med. 1998 Mar;12(2):133-4.

\section{How to cite this article?}

Jain R, Ratre BK, Patel NP. Awareness of palliative care among general practioners of Bhopal: a cross sectional study. Int J Med Res Rev 2017;5(02):144-148. doi:10.17511/ijmrr. 2017.i02.08. 